Supplement of

\title{
Simulations of sulfate-nitrate-ammonium (SNA) aerosols during the extreme haze events over northern China in October 2014
}

Dan Chen et al.

Correspondence to: Zhiquan Liu (liuz@ucar.edu) and Dan Chen (dchen@ucar.edu)

The copyright of individual parts of the supplement might differ from the CC-BY 3.0 licence. 

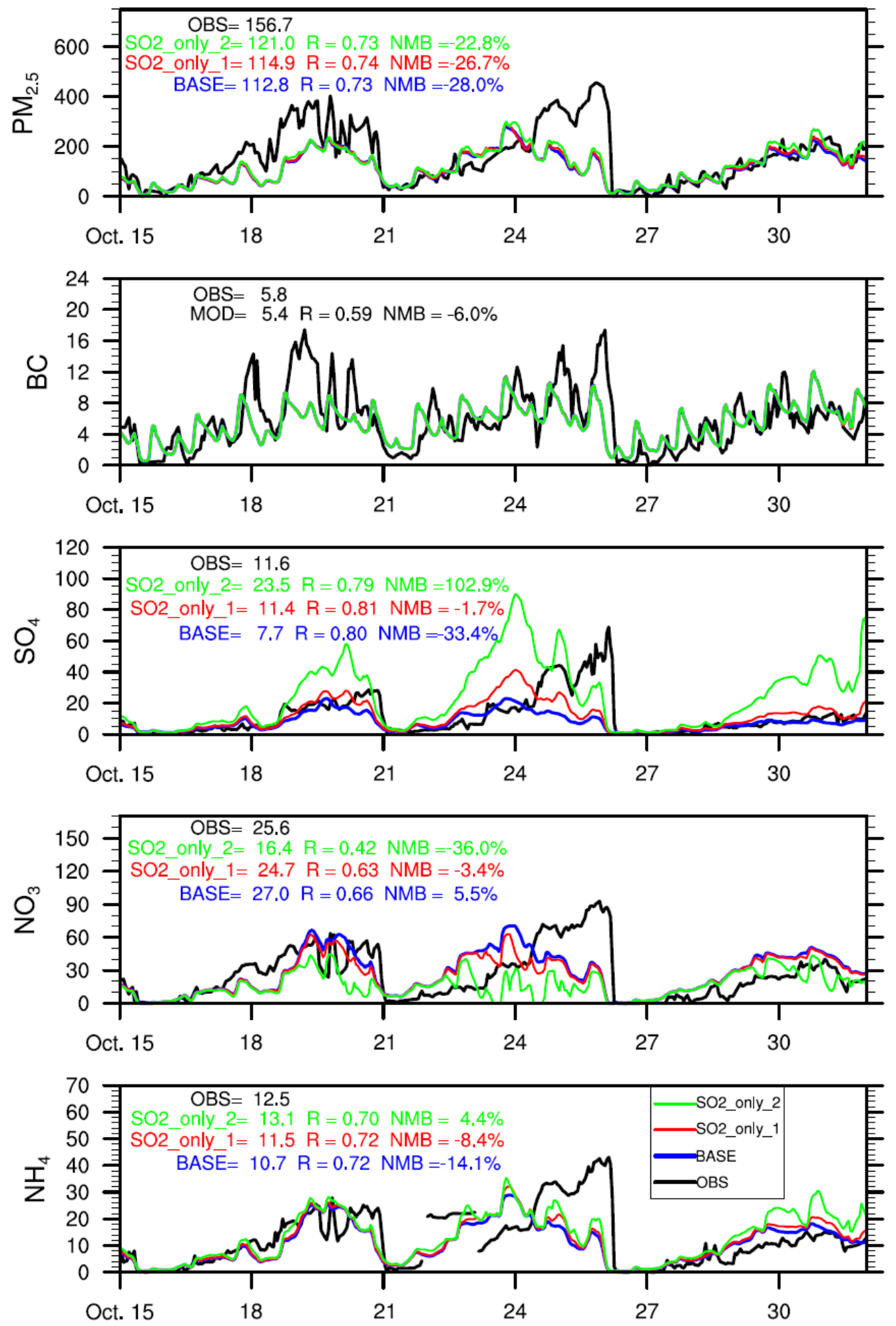

Figure S1. Same as Figure 6 but for the BASE, SO2_only_1, and SO2_only_2 simulations (units: $\mu \mathrm{g} \mathrm{m}^{-3}$ ). SO2_only_1 with lower/upper limits $2 \times 10^{-5} / 5 \times 10^{-5}$; $\mathrm{SO}_{2}$ _only_2 with lower/upper limits $1.0 \times 10^{-4} / 2.6 \times 10^{-4}$. 